\title{
Studies on Management Accounting Informatization Strategy Based on Financial Shared Service
}

\author{
Hongli Peng \\ Economics and Management School of Chuxiong Normal University, Chuxiong Yunnan, 675000, China
}

Keywords: Financial shared service, Management accounting, Informatization.

\begin{abstract}
This paper has started from the overview of financial shared service and management accounting informatization to analyze the importance of financial shared service on management accounting informatization, summarized the problems existing in current enterprise management accounting informatization. In addition, it briefly introduced the management accounting informatization strategies based on financial shared service, aiming at promoting the development of Chinese management accounting informatization and achieving the goal of enterprise refined and standardized financial management.
\end{abstract}

\section{Introduction}

Management accounting informatization is the powerful measure to guarantee enterprise financial refining and standardization. Management accounting can effectively reduce enterprise management accounting cost and improve economic benefits. Thus enterprise should correctly know the importance of management accounting and strengthen management accounting informatization construction so as to highlight the practical function and effect of management accounting and promote enterprise development.

\section{Overview of financial shared service and management accounting informatization}

\subsection{Overview of financial shared service}

Financial shared service, i.e. the manifestation of distributed management mode in financial work which is based on modern information technology to strengthen the optimization of enterprise financial work flow so as to achieve the sustainable of enterprise interior organization structure, system standard and operation procedure. Although financial shared service is aimed at enterprise financial work, in terms of the current developmental trend, it is not only limited to financial accounting work but targeting at enterprise management and operation as a service oriented in enterprise strategic development. Based on enterprise financial management, financial shared service is to integrate enterprise interior various financial accounting data to establish the enterprise financial summarized data so as to help enterprise financial personnel and management accounting personnel to carry out various work. It can be seen that financial shared service integrating two big sections, enterprise financial management and operation management plays an important role for enterprise development. Thus, financial share service is the current global tendency for financial work development, as well as an important subject in front of enterprise development in the future.

\subsection{Overview of management accounting informatization}

As mentioned above, financial management is the highly comprehensive embodiment of enterprise financial and management work. So is management accounting which as the branch of accounting system is different with traditional financial accounting. Based on enterprise financial condition, it can analyze enterprise interior polities and planning condition for the purpose of improving enterprise production and operation activity effect. It plays the role of improving enterprise economic benefits and management efficiency. It can be seen that management accounting 
and financial shared service have similar functions and overlapped working range. Thus under the perspective of financial shared service, it is necessary to strengthen enterprise management accounting informatization, improve the macro property and effectiveness of management accounting work, break the limitation of traditional management accounting work pattern with the help of modern information technology and digital technology so as to effectively control and allocate enterprise interior operation and management work and finally promote enterprise sustainable and stable development.

\section{Importance of financial shared service on management accounting informatization}

Enterprise financial work standardization and refinement through financial shared service is good for promoting enterprise management accounting work efficiency and assisting enterprise management accounting to optimize interior work so as to reduce management accounting workload and further improve financial management accounting working quality. Meanwhile, enterprise use financial shared service platform to promote enterprise financial management accounting informatization, establish effective channel between financial shared center with enterprise departments and posts so as to effectively carry forward enterprise financial work such as enterprise online banking, interior exchange network, enterprise financial auditing, enterprise risk control, enterprise online reimbursement, etc. Above work can be connected through financial shared service to establish a good situation of harmonious development and promote enterprise financial informatization and modernization so as to break the limitation between interior departments and reduce enterprise financial informatization cost.

\section{Problems existing in current management accounting informatization}

Firstly, enterprise management accounting receives insufficient attention. Current economic development mode has influenced management accounting popularization and promotion, thus some enterprises pay no attention to management accounting especially some small and medium-sized enterprises which cannot realize the importance of management accounting so as to influence the development of Chinese enterprise management accounting. Regarding the current enterprise financial condition, some enterprises still have traditional understanding of financial accounting in the stage of financial auditing and statement compilation. In fact, the importance of management accounting is more prominent during the process of enterprise refinement and modernized development. Strengthening the construction of management accounting is good for enterprise development. Secondly, enterprise management accounting investment cost is high as it depends on enterprise cost accounting as the analyzer and researcher of enterprise interior operation and management condition. Its primary working target is to improve enterprise economic benefit. But during the process of establishing management accounting informatization, the early purchasing cost is high. Some enterprises do not recognize large fund investment as they don't realize the importance of financial management accounting. They think management accounting informatization construction has increased enterprise operation cost and fail to research management accounting work in a long run so as to cause the low management accounting informatization construction level. Thirdly, enterprise financial shared information has safety risk. The management accounting informatization system is based on network and enterprise interior data information are expressed in network, which causes high network security danger to enterprise data information. Once leakage, enterprise will have serious loss. Considering this, some enterprises refuse to carry out financial shared work. Fourthly, enterprise financial shared teams are absent. Financial shared service set high requirements for personnel, but some enterprises do not have modern and refined financial management personnel team so that they cannot guarantee the smooth implementation of financial shared work which serious influences the financial shared work effect.

\section{Management accounting informatization strategy based on financial shared service}




\subsection{Enterprise should optimize the overall design of financial shared service}

Before officially carrying out financial shared service, enterprises should optimize designing its interior management accounting and financial scheme so as to provide good environmental support for efficient operation of financial shared work. Firstly, enterprise should establish financial shared service management accounting organizational structure. It is known to all that financial work as the important component of enterprise development requires to strengthen the connection and function between interior divisions so as to establish effective communication mechanism between departments and personnel so as to create a mutual exchange situation inside enterprise and guarantee the implementation and practice of management accounting work in the future. On one hand, enterprise need to change current organizational structure, establish network and modern interior structure system, and establish a mutually supervisory and coordinated interior environment. On the other hand, enterprise should strengthen the management accounting publicity work and establish diversified financial policy publicity channels so that employees can correctly know the importance of management accounting so as to achieve the coordinated development of management accounting work. Secondly, enterprise should optimize current financial work flow. Financial has large workload and long procedures with great complication but it is especially in modern enterprise financial work. So enterprise should sort out the current financial work procedure based on own practical situation and make systematic reform in macro level so that enterprise financial work flow fits well with the requirements of management accounting work . In addition, modern financial management theory has high requirement for target. Enterprises must combine current competition condition to set the financial work target in line with the current situation based on strategic development tendency for specific division so as to clarify the post duty and work procedure of each financial work position. By this mans, it can promote reasonable and refined financial accounting work as the important guarantee factor to construct enterprise management accounting system.

\subsection{Enterprise should establish interior financial risk control system}

Enterprise should establish financial risk management mechanism. Enterprises are faced up to high market risk and financial risk so that tiny decision in production and operation period will result in enterprise into risks. Risk control is the key part for management accounting work but risk control requires for cooperation of financial accounting personnel so as to establish a coordinated development situation for financial shared service to play an important role. Thus, enterprise should correctly realize the importance of risk management, conduct risk control based on interior environment and exterior environment, and optimize interior management policies especially on capital management, financial auditing, tax control, market analysis, legal policies fields, and actively strengthen management and supervision with modern enterprise risk control theory so as to establish a sound enterprise risk control system. To guarantee the interior financial risk control effect, enterprise can effectively improve enterprise financial personnel's activity through perfect performance evaluation so as to improve the working efficiency and effectively control financial risk. The attention of management accounting work to enterprise cost and effectiveness in addition to performance evaluation system can help financial accounting personnel to strengthen cost and effectiveness control and finally increase enterprise economic benefits. Thus, enterprise should establish the penalty and reward system and performance evaluation system. In this system, targeting at financial personnel with high work efficiency and good income and expense control, enterprise should give a certain material encouragement and spiritual rewards so as to motivate financial accounting personnel to devote into work and assist financial accounting work so as to promote enterprise development.

\subsection{Enterprise should pay attention to management accounting informatization safety protection}

Management accounting in financial shared service platform, through integrating enterprise interior financial and management data in the system platform, enterprise can establish scientific, 
comprehensive and purposeful financial and management suggestions including budge management suggestions, cost management suggestion and performance evaluation suggestions. Above reasonable suggestions are important basis for enterprise adjustment policies and managing direction. During this process, management accounting must depend on network to obtain information in financial shared service platform so as to carry out different work. Enterprise interior data information can be transmitted to financial shared platform server through computer terminal with high requirements for enterprise information security. Thus, during the process of promoting management accounting informatization, enterprise should realize the importance of information security protection work to maintain enterprise information safety. Firstly, establish data visit permission system. Enterprise with strong data information confidentiality in the process of operation and development will face up to enterprise operation crisis once leakage. For above data information, enterprise should strengthen database construction and differently process different levels of information, provide different permission for relevant management personnel so as to improve enterprise data information security. Secondly, strengthen management accounting network safety awareness. With a lot of enterprise data information controlled by management accounting, enterprise should cultivate management accounting informatization awareness to guarantee above data information security and apply management accounting into different means through education training so as to increase data information security. On the other hand, enterprises can guarantee information security through firewall, antivirus software and visit key and other measures, and apply above measures and techniques into management accounting training so that enterprises can correctly use modern network safe means to carry out work.On the other hand, enterprise should strengthen supervision and management work of key posts, and install real-time monitoring software in computer of financing, accounting and management posts. Once data information leakage, they can know the leakage process through monitoring software so as to safeguard enterprise financial shared data information security.

\section{Conclusions}

To sum up, management accounting informatization can improve working efficiency and it is an inevitable trend of modern enterprise work development. Financial shared service mode can promote management accounting informatization, effectively reduce enterprise production operation management cost, and improve enterprise economic efficiency and finally promote the standardized and refined development of enterprise financial management work.

\section{References}

[1] Xiong Lei. Effective implementation strategy of management accounting informatization under financial shared service, Friends of Accounting, 2015(8):7-9.

[2] Xu Hanyou, Jiang Yalin, Zhang Pei. "Studies on management accounting informatization under Internet+--from the perspective of financial shared service”, Modern Accounting, 2016(1):28-32.

[3] Lu Xiumei, Zhang Liangwen. Studies on management accounting informatization based on financial shared service, Jiangxi Building Materials, 2017(14):213-214.

[4] Liu Yapeng, Lin Jie, Zhang Rong. Exploration effective implementation of management accounting informatization under financial shared service, China Journal of Commerce, 2015 (19):43-45.

[5] Ge Zhenbo. "Studies on management accounting informatization in the era of Internet+--From the perspective of financial shared service”, China Business Update, 2017(11):178-179.

[6] Yan Wei. Strategies of effectively implementing management accounting informatization under financial shared service [J]. Corporate Culture (mid-periodical journal), 2016(1): 175,177.

[7] Xi Jing. Studies on Chinese enterprise financial shared service application---based on the 
background of management accounting informatization, China Management Informationization, 2016,19(23):49-51.

[8] Li Zhengdong. Discussion on effective implementation strategies of management accounting informatization under financial shared service, Market Modernization, 2015(29):158-159.

[9] Dong Manli. Strategies on effective implementation strategies of management accounting informatization under financial shared service, Global Market, 2017(25):83. 